\title{
Menopausal hot flashes: The role of magnesium and select endocrine factors
}

\author{
Maya Orlofsky, Serin Seckin* and Ozgul Muneyyirci-Delale \\ Department of Obstetrics and Gynecology, SUNY Downstate Medical Center, Brooklyn, NY 11203, USA
}

\begin{abstract}
Hot flashes are a highly prevalent and distressing symptom experienced in menopause, but very little is known about their pathogenesis. Hypomagnesemia may be involved in menopausal hot flashes, but there is a dearth of research in this area. Certain hormones such as insulin, ghrelin, and melatonin, as well as adipokine factors, may also be involved.

A systematic search was conducted using key words including menopause, hot flashes, vasomotor symptoms, ionized magnesium, ionized calcium to magnesium ratio, insulin resistance, adipokine and ghrelin levels, and melatonin. Articles were included if they used human subjects, female subjects, and were published in English. Articles were excluded if they were published prior to the year 1990, if they were review articles, or if the article was not relevant to the current review.

691 articles were found and, after exclusion of studies based on the above criteria, 17 articles were included in the review. 8,667 patients were collectively represented. Magnesium supplementation for hot flashes demonstrated mixed results, with one study showing improvement of symptoms and another study showing no significant improvement. Hypomagnesemia and hot flashes were separately found to be associated with increased insulin resistance, increased adipokine levels, and increased ghrelin levels. Melatonin supplementation was not found to improve hot flash symptoms.

Few studies have directly researched the relationship between magnesium and menopausal hot flashes, and the results have been inconclusive. Stronger relationships have been found between hot flashes and increased insulin resistance, adipokine, and ghrelin levels. Further research is needed, as these findings may indicate future novel treatment options for menopausal hot flashes.
\end{abstract}

\section{Introduction}

Hot flashes are one of the most common complaints in menopause, with up to $79 \%$ of women experiencing hot flashes by completion of the menopausal transition [1]. They can have significant effects on quality of life; links have been demonstrated between hot flashes and depressed mood, sleep disturbances, cardiovascular health, and bone health [2].

One area of research that has not been extensively studied is that of the role of ionized magnesium $\left(\mathrm{Mg}^{2+}\right)$ in the physiology of menopausal hot flashes. Magnesium is a cofactor in over 600 known enzymatic reactions in the body, with ionized magnesium $\left(\mathrm{Mg}^{2+}\right)$ as the most biologically active form [3]. Low ionized magnesium levels have been demonstrated in patients with chronic renal failure, asthma, pre-eclampsia, and patients hospitalized in the intensive care unit [47]. Hypomagnesemia in menopause may lead to deleterious effects throughout the body. Menopausal women with hypomagnesemia were found to have increased thyroid-stimulating hormone (TSH), which could lead to clinical hypothyroidism [8]. Magnesium has been found to be involved in serotonin and norepinephrine transmission, and therefore hypomagnesemia may be involved in depression, a common comorbidity of menopause. Magnesium may additionally reduce adrenocorticotrophic hormone (ACTH) activity, thus hypomagnesemia may cause an increased release of cortisol in response to stress [9]. Magnesium has also been shown to increase the synthesis of nitric oxide, an important vasodilator [10].

In this literature review, the hypothesis that hypomagnesemia as well as altered levels of other endocrine factors are involved in the pathophysiology of menopausal hot flashes will be investigated.
Our focus lies mainly on magnesium. However, due to the dearth of studies on its role in hot flashes, this review was expanded to include other endocrine factors with which magnesium is known to have an association, such as insulin, adipokines, ghrelin, and melatonin.

\section{Materials and methods}

In conducting this literature review, systematic online searches were conducted by two separate reviewers through PubMed, MEDLINE, and Google Scholar. Additionally, the textbook "Clinical Gynecologic Endocrinology and Infertility" was used as a reference [11]. Search terms included "menopause and magnesium", "hot flashes and magnesium", "vasomotor symptoms and magnesium", "ionized magnesium and menopause", "ionized calcium to magnesium ratio and menopause", "insulin resistance and magnesium", "insulin resistance and hot flashes", "adipokines and magnesium", "adipokines and hot flashes", "ghrelin and magnesium", "ghrelin and hot flashes", "melatonin and magnesium", and "melatonin and hot flashes". Articles were included if they used human subjects, female subjects, and were published in English. Articles were excluded if they were published prior to the year 1990, if they were review articles, or if the article was not relevant to the current review. Quality of the evidence was assessed using the scheme set by the Oxford

${ }^{\star}$ Correspondence to: Dr. Serin Seckin, M.D., 450 Clarkson Avenue, Department of OB/GYN, Brooklyn, NY 11203, USA, E-mail: serin.i.seckin@gmail.com

Key words: hot flashes, menopause, magnesium, insulin, adipokines, melatonin

Received: May 16, 2021; Accepted: June 02, 2021; Published: June 07, 2021 
Centre for Evidence-Based Medicine, with 1 being the highest quality and 5 being the lowest quality [12].

\section{Results}

In total, 691 articles were found, 674 were excluded based on the above criteria, and the following 17 articles were reviewed. These 17 studies included 4 randomized control trials, 1 non-randomized control trial, 2 prospective cohort studies, 5 prospective case-control studies, 1 two-part prospective case-control and cross-sectional study, and 4 cross-sectional studies. In total, 8667 patients were collectively represented by these studies. The following sections are titled by the keywords used in each search.

1. Menopause, magnesium, ionized magnesium, ionized calcium to magnesium ratio

In this search, only one prospective study by Muneyyirci-Delale et al. was found (Table 1). This study looked at ionized magnesium levels and the ionized calcium to magnesium ratio in menopausal and pre-menopausal women. Pre-menopausal women were evaluated in both follicular and ovulatory phases. Menopausal women had higher magnesium and calcium levels compared to pre-menopausal women. Magnesium levels inversely correlated with estrogen levels in both pre-menopausal and menopausal women. The ionized calcium to magnesium ratio increased as estrogen increased but was not found to be elevated in either pre-menopausal or menopausal women [13].

\section{Hot flashes and magnesium}

In this search, two studies from the Park et al. [14] group were examined, in which patients experiencing hot flashes were given supplemental magnesium (Table 2). In the phase II trial $(\mathrm{n}=25)$, treatment with $400-800 \mathrm{mg}$ of magnesium oxide was successful in reducing hot flashes. The larger randomized control study $(n=289)$ using treatment with 800 or $1200 \mathrm{mg}$ of magnesium oxide yielded some improvement in symptoms, with $1200 \mathrm{mg}$ doses being slightly more effective, but this improvement was not significant in comparison to placebo [15].

\section{Magnesium, insulin resistance, menopause, and hot flashes}

In this search, 8 studies were found (Table 3). Four of these studies examined the relationship between hypomagnesemia and type 2 diabetes. Lower magnesium levels in diabetic patients were demonstrated in two studies, with one prospective study specifically assessing ionized magnesium $[16,17]$. Lecube et al. [18] similarly found in a two-part cross-sectional and prospective study that as diabetes resolved in obese patients after bariatric surgery, their magnesium levels increased [18]. Another randomized control study demonstrated that magnesium supplementation improved the glycemic status of prediabetic patients [19]. Two studies were found that examined magnesium levels and insulin resistance. One prospective study showed that patients with lower ionized magnesium levels showed decreased insulin sensitivity [20]. Another group used the homeostasis model assessment of insulin resistance (HOMA-IR) to show that obese women with lower intracellular magnesium levels had increased insulin resistance in a prospective study [21]. Finally, two studies specifically assessed insulin resistance in menopause. A smaller prospective study by Tuomikoski et al. [22] $(\mathrm{n}=131)$ found no association between insulin resistance and hot flashes, although insulin resistance did negatively correlate with estradiol levels. A larger longitudinal cohort study using

Table 1. Menopause, magnesium, ionized magnesium, ionized calcium to magnesium ratio

\begin{tabular}{|l|c|c|c|}
\hline Author(s) & Year Published & Study Type & Quality Rating \\
\hline Muneyyirci-Delale O, et al. [13] & 1999 & Prospective case-control study & $\begin{array}{c}\text { In menopausal women, magnesium levels inversely } \\
\text { correlated with estrogen, serum calcium levels were } \\
\text { elevated, and the ionized calcium to magnesium } \\
\text { ratio was not elevated. }\end{array}$ \\
\hline
\end{tabular}

Table 2. Hot flashes and magnesium

\begin{tabular}{|l|c|c|c|c|}
\hline Author(s) & Year Published & Study Type & Quality Rating & Summary of Findings \\
\hline Park H, et al. $[14]$ & 2011 & Pilot phase II non-randomized clinical trial & 2 & $\begin{array}{c}\text { Breast cancer patients with hot flashes were successfully treated } \\
\text { with magnesium. }\end{array}$ \\
\hline Park H, et al. $[15]$ & 2015 & Double-blinded randomized-control trial & 1 & $\begin{array}{c}\text { Breast cancer patients with hot flashes were treated with } \\
\text { magnesium but did not have significant improvement. }\end{array}$ \\
\hline
\end{tabular}

Table 3. Magnesium, insulin resistance, menopause, and hot flashes

\begin{tabular}{|c|c|c|c|c|}
\hline Author(s) & Year Published & Study Type & Quality Rating & Summary of Findings \\
\hline Resnick LM, et al. [17] & 1993 & Prospective case-control study & 3 & $\begin{array}{l}\text { Type } 2 \text { diabetic patients were found to have lower levels of serum ionized } \\
\text { magnesium and intracellular free magnesium than non-diabetic controls. }\end{array}$ \\
\hline Barbagallo M, et al. [20] & 1997 & Prospective case-control study & 3 & $\begin{array}{l}\text { Hypertensive subjects were found to have lower basal ionized magnesium levels, } \\
\text { which correlated with lower cellular responsiveness to insulin. }\end{array}$ \\
\hline Lecube A, et al. [18] & 2012 & $\begin{array}{l}\text { Cross-sectional case-control study } \\
\text { and prospective case-control study }\end{array}$ & $4 ; 3$ & $\begin{array}{c}\text { Obese subjects that underwent bariatric surgery and whose diabetes subsequently } \\
\text { resolved had increases in magnesium levels. }\end{array}$ \\
\hline Tuomikoski P, et al. [22] & 2012 & Prospective case-control study & 3 & $\begin{array}{l}\text { Menopausal women were found to have no association between hot flashes and } \\
\text { insulin levels, glucose levels, or insulin resistance. Insulin resistance was found to } \\
\text { have a negative correlation with estradiol levels. }\end{array}$ \\
\hline Thurston R, et al. [23] & 2012 & $\begin{array}{l}\text { Prospective } \\
\text { longitudinal cohort study }\end{array}$ & 2 & $\begin{array}{c}\text { Participants in SWAN cohort with hot flashes had associated increased insulin } \\
\text { resistance. }\end{array}$ \\
\hline Cruz K, et al. [21] & 2014 & Prospective case-control study & 3 & $\begin{array}{l}\text { Obese women were found to have a negative correlation between erythrocyte } \\
\text { magnesium and insulin resistance. }\end{array}$ \\
\hline $\begin{array}{l}\text { Guerrero-Romero F, et al. } \\
{[19]}\end{array}$ & 2015 & $\begin{array}{l}\text { Double-blinded randomized-control } \\
\text { trial }\end{array}$ & 1 & $\begin{array}{l}\text { Prediabetic patients with hypomagnesemia had reduced plasma glucose and } \\
\text { improved glycemic status after being given magnesium supplementation. }\end{array}$ \\
\hline Wei J, et al. [16] & 2016 & Cross-sectional study & 4 & $\begin{array}{l}\text { Serum magnesium was found to be inversely correlated with diabetes in a Chinese } \\
\text { population, but dietary magnesium was not significantly correlated. }\end{array}$ \\
\hline
\end{tabular}


Table 4. Hot flashes, adipokine, and ghrelin levels

\begin{tabular}{|l|c|c|c|c|}
\hline Author(s) & Year Published & Study Type & Quality Rating & \multicolumn{1}{|c|}{ Summary of Findings } \\
\hline Alexander C, et al. [24] & 2010 & Cross-sectional study & 4 & $\begin{array}{c}\text { Midlife, premenopausal women were found to have positive correlations } \\
\text { between leptin levels and hot flash occurrence and duration. }\end{array}$ \\
\hline Thurston R, et al. [25] & 2013 & Prospective longitudinal cohort study & 2 & $\begin{array}{c}\text { Participants in SWAN cohort with adverse adipokine profiles had more } \\
\text { hot flashes. }\end{array}$ \\
\hline Huang, WY, et al. [26] & 2017 & Cross-sectional study & 4 & $\begin{array}{c}\text { Women who experienced hot flashes had higher levels of adipokines and } \\
\text { higher insulin resistance. }\end{array}$ \\
\hline Karim R, et al. [27] & 2020 & $\begin{array}{c}\text { Post-hoc cross-sectional study using data } \\
\text { from two clinical trials }\end{array}$ & 4 & $\begin{array}{c}\text { Menopausal women with hot flashes were found to have higher levels of } \\
\text { ghrelin, but leptin, adiponectin, and resistin levels were not associated. }\end{array}$ \\
\hline
\end{tabular}

Table 5. Hot flashes and melatonin

\begin{tabular}{|l|c|c|c|c|}
\hline Author(s) & Year Published & Study Type & Quality Rating & Summary of Findings \\
\hline Secreto G, et al. [28] & 2004 & Double-blinded randomized-control trial & 1 & $\begin{array}{c}\text { Treatment of menopausal women with melatonin did not show any } \\
\text { advantage in relief of symptoms in comparison to placebo. }\end{array}$ \\
\hline Chen WY, et al. [29] & 2014 & Randomized control trial & 1 & $\begin{array}{c}\text { Melatonin supplementation in menopausal breast cancer survivors was } \\
\text { associated with increased subjective sleep quality in comparison to placebo, } \\
\text { but no significant change in hot flash symptoms. }\end{array}$ \\
\hline
\end{tabular}

data from the Study of Women's Health Across the Nation (SWAN) (n $=3075$ ) found conflicting results, with a significant association between insulin resistance and menopausal hot flashes [23].

\section{Hot flashes, adipokine, and ghrelin levels}

In this search, 4 studies were found (Table 4). Two of these studies showed higher leptin levels in women experiencing hot flashes, whether or not they had reached menopausal status; one cross-sectional study analyzed a group of premenopausal women $(n=211)$ and one longitudinal cohort study assessed a group of women early in their menopausal transition $(\mathrm{n}=536)$ [24,25]. Huang et al. [26] found in a cross-sectional study $(\mathrm{n}=151)$ that not only did women with hot flashes have higher leptin levels, but also increased insulin resistance using the HOMA-IR. Finally, a recent cross-sectional study $(\mathrm{n}=898)$ discovered that women with hot flashes who were menopausal did not have increased leptin levels, in contrast to the previous study, but did have increased ghrelin levels [27].

\section{Hot flashes and melatonin}

In this search, 2 studies were found (Table 5). Both randomized control studies evaluated the effect of supplementation of melatonin on menopausal hot flashes, and both studies found that there was no significant relief of symptoms with this treatment. Women with menopausal hot flashes were found to have increased sleep quality with melatonin treatment by Chen et al. [28,29].

\section{Pathophysiology}

The physiological mechanism behind hot flashes is not completely understood. It is thought that an increase in hypothalamic thermosensitivity narrows the range within which the hypothalamus perceives as normal core temperature, causing a lowering of the sweat threshold and elevation of the shivering threshold. Thus, small increases in body temperature will trigger a supernormal heat dissipation response, including peripheral vasodilation and sweating, manifested as a hot flash [30]. Sex hormones are likely involved in the pathogenesis of hot flashes as lower levels of estrogen have been observed in women experiencing menopausal hot flashes [31]. However, hot flashes are not experienced in prepubertal females who also have low levels of estrogen. Thus, exposure to adult levels of estrogen and then subsequent withdrawal may be more crucial to the formation of vasomotor symptoms than hypoestrogenism itself [32]. A study in rats found that estradiol may act on the ventromedial nucleus of the hypothalamus to inhibit thermogenesis and decrease energy expenditure. Therefore, it is possible that in an estrogen-depleted state core temperature can become dysregulated [33].

Other hormones may also play a role: higher follicle-stimulating hormone (FSH) concentrations have been shown to be associated with increased hot flash symptoms [34]. Pulsatile release of luteinizing hormone (LH) was found to be synchronized with the onset of hot flashes, and more recently it was discovered that neurons co-expressing kisspeptin, neurokinin B, and dynorphin (KNDy neurons) are involved in both generating $\mathrm{LH}$ pulses and thermoregulation. These are thermoregulatory neurons found in the arcuate nucleus of the hypothalamus that express estrogen receptors and become hypertrophied in the absence of estrogen, and therefore may be of relevance in the development of hot flashes in the estrogen-depleted state of menopause [35-37].

Obesity is strongly associated with hot flashes. Increased levels of adipose tissue were previously thought to be protective against hot flashes due to increased androgen aromatization to estrogens in said tissue, but it appears the opposite is true [2]. Levels of adipokines - signaling proteins that are secreted from adipose tissue - have been found to increase during menopause and may be involved in the pathogenesis of hot flashes. This may further explain why obesity is a major risk factor for hot flashes $[24,38]$. Other risk factors for hot flashes include smoking, AfricanAmerican ethnicity, lower socioeconomic status, history of depression or anxiety, and history of experiencing child abuse [2,39].

Neurotransmitters may also be involved. Melatonin levels were found to be decreased during menopause, which may be related to the increased nocturnal awakenings associated with hot flashes [40]. Norepinephrine metabolite levels were shown to be increased before and during hot flashes [41]. Conversely, administration of clonidine, an $\alpha_{2}$-adrenergic agonist, has been demonstrated provide relief of hot flashes [42]. Decreased estrogen also correlates with decreased serotonin levels and upregulation of hypothalamic serotonin receptors, some of which may be involved in heat loss mechanisms $[43,44]$. These findings are consistent with the idea that hot flashes are mediated centrally.

\section{Clinical presentation}

Typical symptoms experienced during a hot flash include a sudden feeling of heat in the chest and face that then spreads throughout the body, as well as sweating and palpitations. This lasts for a few minutes and can then be followed by chills and shivering [2]. Hot flashes are also associated with increased nocturnal awakening [45]. 


\section{Assessment and diagnosis}

The diagnosis of hot flashes is usually clinical, but there are also measurement techniques for hot flashes as well. Subjective measurements of hot flashes can be done by questionnaires that assess for factors such as frequency, severity, and associated symptoms. Objective measurements of hot flashes include analysis of sternal skin conductance and sweat levels via hot flash monitors [46].

\section{Treatment}

Current pharmacologic treatments include hormone therapy, such as estrogen therapy, as well as antidepressants including selective serotonin reuptake inhibitors (SSRIs) and serotonin-norepinephrine reuptake inhibitors (SNRIs), clonidine, and gabapentin [47]. Continuous transdermal nitroglycerin is a new experimental treatment for hot flashes that works by tolerance-induced suppression of nitric oxidemediated vasodilation [48]. Treatments that target the KNDy system are also currently being studied $[49,50]$. Some women are unable to use hormone therapy as treatment due to contraindications to exogenous estrogen, such as those with a history of breast cancer, therefore it is important to study other possible treatments for hot flashes [51].

\section{Prognosis}

Symptoms of hot flashes may persist frequently for over seven years, as was demonstrated by the SWAN study. Hot flashes were reported for about 4.5 years after patients' final menstrual period [52].

\section{Discussion}

After reviewing the current literature, it appears there is some evidence that supports the hypothesis of hypomagnesemia involvement in the pathophysiology of menopausal hot flashes. Only one study by Muneyyirci-Delale $\mathrm{O}$ et al. was found to evaluate the levels of ionized magnesium $\left(\mathrm{Mg}^{2+}\right)$ in menopausal women, and hot flash experience was not assessed. $\mathrm{Mg}^{2+}$ was found to increase with the menopausal decrease in estrogen, which was theorized to be protective, as higher $\mathrm{Mg}^{2+}$ facilitates lower blood pressure and lower peripheral resistance, effects that would have previously been carried out by estrogen. This may be necessary due to increased cardiovascular contractility in menopause due to increased calcium ions $\left(\mathrm{Ca}^{2+}\right)$ from increased bone metabolism [13]. Thus, it appears that magnesium levels change with menopause, but it is not clear if this is related to hot flashes. Two studies were found in which women with hot flashes were given supplemental magnesium with conflicting results [14,15]. A later review pointed out, though, that only women with hot flashes induced by breast cancer pharmacotherapy were evaluated, rather than those with age-related menopause [53]. Furthermore, these trials did not assess whether hypomagnesemia was involved in the development of hot flashes, nor did they specifically measure ionized magnesium $\left(\mathrm{Mg}^{2+}\right)$ levels. It is difficult to assess magnesium activity because most magnesium is intracellular, so erythrocyte intracellular magnesium levels is a target that perhaps should be additionally measured [54].

Another similar area of interest within hot flash physiology is that of the ionized calcium to magnesium ratio $\left(\mathrm{Ca}^{2+}: \mathrm{Mg}^{2+}\right)$. As previously stated, $\mathrm{Ca}^{2+}$ and $\mathrm{Mg}^{2+}$ levels are known to rise in menopause [13]. Increases in $\mathrm{Ca}^{2+}: \mathrm{Mg}^{2+}$, however, have been associated with vasospasm, a major risk factor in strokes, hypertension, pre-eclampsia, asthma, and sickle cell anemia [5-7,55,56]. Muneyyirci-Delale $\mathrm{O}$ et al. also assessed this ratio in menopausal women and it was not found to be elevated. It was theorized that this is protective, as described above [13]. However, menopausal hot flashes may be due to hypomagnesemia, and therefore it would follow that these women have higher $\mathrm{Ca}^{2+}: \mathrm{Mg}^{2+}$. Women with hot flashes may then be at risk for conditions related to vasospasm, but further investigation is needed. As mentioned earlier, hot flashes have been found to be associated with cardiovascular disease and dysfunction [57,58].

Certain endocrine factors, including insulin, adipokines, ghrelin, and melatonin, may also be involved in the pathogenesis of menopausal hot flashes, which is the latter portion of our hypothesis in this review. This association was supported by many of the reviewed articles. In addition, many of these hormones and factors were found to also have a relationship with magnesium, suggesting an interplay between these pathways.

Multiple studies in this review showed that diabetic subjects were found to have significantly lower levels of serum magnesium than nondiabetic controls, and intracellular magnesium was found to inversely correlate with glycemic control [16,18,21]. Magnesium supplementation has also been found to potentially reduce insulin resistance [19,59]. Increased levels of insulin also appear to increase renal magnesium excretion. Thus, insulin resistance and type 2 diabetes may precipitate the development of hypomagnesemia [60]. This potentially underlies an older hypothesis that obesity was associated with hypomagnesemia, but it may be due to the common comorbidity of diabetes [18]. Since hypomagnesemia may also be involved in hot flashes, menopausal women experiencing hot flashes may be at risk for increased insulin resistance, and vice versa. However, one study that examined this potential relationship between menopause and diabetes risk found no significant association [61]. Two studies found in this review examined the relationship between hot flashes and insulin resistance with conflicting results, possibly due to a difference in sample size [22,23]. Interestingly, kisspeptin levels have been found to inversely correlate with insulin secretion, and therefore the increased kisspeptin levels seen in menopause may cause decreased insulin levels [62]. Additionally, decreased levels of nitric oxide were found to cause increased insulin clearance [63].

Adipokines, such as leptin, adiponectin, and resistin, as well as the related gastric hormone ghrelin, were investigated for their possible role in the pathogenesis of hot flashes. Higher leptin levels were found to be correlated with worse experiences of hot flashes in three of the four studies reviewed [24-26]. Karim et al. [27] did not find a correlation between leptin levels and hot flash intensity, but they attributed that to their cohort being relatively older. Animal studies have found leptin to be involved in hypothalamic thermoregulation and energy expenditure [64,65]. Leptin levels are increased in people with higher amounts of adipose tissue, which may be part of why hot flashes are associated with obesity [25]. Other adipokines have also been investigated. Low adiponectin was found to be associated with hot flashes, but resistin levels had no significant association $[25,26]$. A study in mice showed that adiponectin may have an inverse relationship with body temperature [66]. In the study of older menopausal women, ghrelin was also found to be increased with hot flashes. It was theorized that ghrelin may play a role in hypothalamic thermoregulation via modulation of KNDy neurons [27]. Interestingly, one study found that leptin and adiponectin were also associated with increased insulin resistance in menopausal women [26].

Finally, we investigated if melatonin played a role in menopausal hot flashes. It has been well-established that menopause is associated with changes in sleep, especially insomnia [67]. Hot flashes are a significant cause of sleep impairment in menopause, and low melatonin levels have been found in menopausal women as well. ${ }^{40,55}$ Therefore, it is 
possible that there is a relationship between the two. The studies found in this review, however, showed no significant improvement of hot flash symptoms in menopausal women treated with melatonin. Interestingly, magnesium has been found to improve sleep disturbances in elderly patients $[68,69]$. In another study, women were found to have decreased daytime sleepiness after magnesium supplementation [70]. It may be that hypomagnesemia is involved in sleep disturbance in menopausal hot flashes.

In summary, more research is needed in the pathophysiology of menopausal hot flashes, as well as the potential involvement of magnesium and other endocrine factors. To the best of the authors' knowledge, this is the only review that has investigated and consolidated all these potential contributing factors to present a novel view of the mechanisms underlying menopausal hot flashes.

\section{Limitations}

The major limitation of this literature review is there were very few articles on the topic of menopausal hot flashes and magnesium. Additionally, the only databases used to find articles were PubMed, MEDLINE, and Google Scholar. Finally, the exclusionary criteria applied to the searches also limited the research highlighted in this paper.

\section{Future directions}

There are multiple future directions for research in the topic of menopause and magnesium. First, a study specifically examining the relationship between low levels of magnesium, especially ionized magnesium, and menopausal hot flashes, has not been done. The relationship between hot flashes and the ionized calcium to magnesium ratio has also not been well established. Additionally, the correlations of magnesium and hot flashes to insulin resistance, adipokines, ghrelin, and melatonin have not been thoroughly researched.

\section{Conclusion}

In summary, the relationship between menopausal hot flashes and hypomagnesemia is significantly understudied and warrants further investigation. Few studies discussed in this literature review directly investigated the role of magnesium in hot flashes, and ionized magnesium was rarely measured. However, multiple studies showed that hypomagnesemia and hot flashes separately had similar correlations with insulin resistance, adipokine, and ghrelin levels, thus a relationship between these pathways should be researched further. Future studies may greatly benefit from assessing levels of ionized magnesium to better understand the activity of magnesium in the body and how magnesium is involved in menopausal hot flashes.

\section{Financial disclosures}

The authors declare that they have no financial disclosures.

\section{Conflicts of interest}

The authors declare that they have no conflicts of interest.

\section{Acknowledgements}

None.

\section{Ethical approval}

IRB reviewed and determined to not be human subject's research.

\section{Author contributions}

MO: literature review and analysis, drafting of manuscript, preparation of tables, submission of manuscript.
SS: literature review and analysis, drafting of manuscript.

OMD: oversight and design of literature review and analysis, editing of manuscript.

\section{References}

1. Woods NF, Mitchell ES (2005) Symptoms during the perimenopause: prevalence, severity, trajectory, and significance in women's lives. Am J Med 118 Suppl 12B: 14-24. [Crossref]

2. Thurston RC, Joffe H (2011) Vasomotor symptoms and menopause: findings from the Study of Women's Health across the Nation. Obstet Gynecol Clin North Am 38: 489501. [Crossref]

3. de Baaij JH, Hoenderop JG, Bindels RJ (2015) Magnesium in man: implications for health and disease. Physiol Rev 95: 1-46. [Crossref]

4. Dewitte K, Dhondt A, Giri M, Stöckl D, Rottiers R, et al. (2004) Differences in serum ionized and total magnesium values during chronic renal failure between nondiabetic and diabetic patients: a cross-sectional study. Diabetes Care 27: 2503-2505. [Crossref]

5. Sinert R, Spektor M, Gorlin A, Doty C, Rubin A, et al. (2005) Ionized magnesium levels and the ratio of ionized calcium to magnesium in asthma patients before and after treatment with magnesium. Scand J Clin Lab Invest 65: 659-670. [Crossref]

6. Apostol A, Apostol R, Ali E, Choi A, Ehsuni N, et al. (2010) Cerebral spinal fluid and serum ionized magnesium and calcium levels in preeclamptic women during administration of magnesium sulfate. Fertil Steril 94: 276-282. [Crossref]

7. Resnick LM, Bardicef O, Altura BT, Alderman MH, Altura BM (1997) Serum ionized magnesium: relation to blood pressure and racial factors. Am J Hypertens 10: 1420 1424. [Crossref]

8. Kolanu BR, Vadakedath S, Boddula V, Kandi V (2020) Activities of serum magnesium and thyroid hormones in pre-, peri-, and post-menopausal women. Cureus 12: e6554.

9. Wang J, Um P, Dickerman BA, Liu J (2018) Zinc, magnesium, selenium and depression: a review of the evidence, potential mechanisms and implications. Nutrients 10: 584 [Crossref]

10. Maier JA, Bernardini D, Rayssiguier Y, Mazur A (2004) High concentrations of magnesium modulate vascular endothelial cell behaviour in vitro. Biochim Biophys Acta 1689: 6-12. [Crossref]

11. Taylor HS, Pal L, Seli E, Fritz MA (2020) Speroff's clinical gynecologic endocrinology and infertility. Ninth edition.

12. Group OLoEW (2011) The Oxford Levels of Evidence 2. Oxford Centre for EvidenceBased Medicine.

13. Muneyyirci-Delale O, Nacharaju VL, Dalloul M, Altura BM, Altura BT (1999) Serum ionized magnesium and calcium in women after menopause: inverse relation of estrogen with ionized magnesium. Fertil Steril 71: 869-872.

14. Park H, Parker GL, Boardman CH, Morris MM, Smith TJ (2011) A pilot phase II tria of magnesium supplements to reduce menopausal hot flashes in breast cancer patients. Support Care Cancer 19: 859-863. [Crossref]

15. Park H, Qin R, Smith TJ, Atherton PJ, Barton DL, et al. (2015) North Central Cancer Treatment Group N10C2 (Alliance): a double-blind placebo-controlled study of magnesium supplements to reduce menopausal hot flashes. Menopause 22: 627-632. [Crossref]

16. Wei J, Zeng C, Li XX, Gong QY, Lei GH, Yang TB (2016) Association among dietary magnesium, serum magnesium, and diabetes: a cross-sectional study in middle-aged and older adults. J Health Popul Nutr 35: 33. [Crossref]

17. Resnick LM, Altura BT, Gupta RK, Laragh JH, Alderman MH, et al. (1993) Intracellular and extracellular magnesium depletion in type 2 (non-insulin-dependent) diabetes mellitus. Diabetologia 36: 767-770.

18. Lecube A, Baena-Fustegueras JA, Fort JM, Pelegri D, Hernandez C, et al. (2012) Diabetes is the main factor accounting for hypomagnesemia in obese subjects. PloS One 7: e30599. [Crossref]

19. Guerrero-Romero F, Simental-Mendia LE, Hernandez-Ronquillo G, Rodriguez-Moran M (2015) Oral magnesium supplementation improves glycaemic status in subjects with prediabetes and hypomagnesaemia: A double-blind placebo-controlled randomized trial. Diabetes Metab 41: 202-207. [Crossref]

20. Barbagallo M, Gupta RK, Bardicef O, Bardicef M, Resnick LM (1997) Altered ionic effects of insulin in hypertension: role of basal ion levels in determining cellular responsiveness. J Clin Endocrinol Metab 82: 1761-1765. [Crossref]

21. Cruz KJ, de Oliveira AR, Pinto DP, Morais JBS, da Silva Lima F, et al. (2014) Influence of magnesium on insulin resistance in obese women. Biol Trace Elem Res 160: 305-310. 
22. Tuomikoski P, Ylikorkala O, Mikkola TS (2012) Menopausal hot flashes and insulin resistance. Menopause 19: 1116-1120. [Crossref]

23. Thurston RC, El Khoudary SR, Sutton-Tyrrell K, Crandall CJ, Sternfeld B, et al. (2012) Vasomotor symptoms and insulin resistance in the study of women's health across the nation. J Clin Endocrinol Metab 97: 3487-3494. [Crossref]

24. Alexander C, Cochran CJ, Gallicchio L, Miller SR, Flaws JA, et al. (2010) Serum leptin levels, hormone levels, and hot flashes in midlife women. Fertil Steril 94: 1037-1043. [Crossref]

25. Thurston RC, Chang Y, Mancuso P, Matthews KA (2013) Adipokines, adiposity, and vasomotor symptoms during the menopause transition: findings from the Study of Women's Health Across the Nation. Fertil Steril 100: 793-800. [Crossref]

26. Huang WY, Chang CC, Chen DR, Kor CT, Chen TY, et al. (2017) Circulating leptin and adiponectin are associated with insulin resistance in healthy postmenopausal women with hot flashes. PloS One 12: e0176430.

27. Karim R, Dang HM, Hodis HN, Stanczyk FZ, Brinton RD, et al. (2020) Association of hot flushes with ghrelin and adipokines in early versus late postmenopausal women. Menopause 27: 512-518.

28. Secreto G, Chiechi LM, Amadori A, Miceli R, Venturelli E, et al. (2004) Soy isoflavones and melatonin for the relief of climacteric symptoms: a multicenter, double-blind, randomized study. Maturitas 47: 11-20. [Crossref]

29. Chen WY, Giobbie-Hurder A, Gantman K, Savoie J, Scheib R, et al. (2014) A randomized, placebo-controlled trial of melatonin on breast cancer survivors: impact on sleep, mood, and hot flashes. Breast Cancer Res Treat 145: 381-388. [Crossref]

30. Freedman RR, Krell W (1999) Reduced thermoregulatory null zone in postmenopausal women with hot flashes. Am J Obstet Gynecol 181: 66-70.

31. Ratka A, Miller V, Brown K, Jenschke M, Simpkins J (2009) Association of various dimensions of hot flashes with systemic levels of gonadal steroids. Exp Biol Med (Maywood) 234: 395-402. [Crossref]

32. Freedman RR (2014) Menopausal hot flashes: mechanisms, endocrinology, treatment $J$ Steroid Biochem Mol Biol 142: 115-120. [Crossref]

33. Martinez de Morentin PB, Gonzalez-Garcia I, Martins L, Lage R, Fernández-Mallo D, et al. (2014) Estradiol regulates brown adipose tissue thermogenesis via hypothalamic AMPK. Cell Metab 20: 41-53. [Crossref]

34. Randolph JF, Jr., Sowers M, Bondarenko I, Gold EB, Greendale GA, et al. (2005) The relationship of longitudinal change in reproductive hormones and vasomotor symptoms during the menopausal transition. J Clin Endocrinol Metab 90: 6106-6112. [Crossref]

35. Rance NE, Dacks PA, Mittelman-Smith MA, Romanovsky AA, Krajewski-Hall SJ (2013) Modulation of body temperature and LH secretion by hypothalamic KNDy (kisspeptin, neurokinin B and dynorphin) neurons: a novel hypothesis on the mechanism of hot flushes. Front Neuroendocrinol 34: 211-227. [Crossref]

36. Jayasena CN, Comninos AN, Stefanopoulou E, Buckley A, Narayanaswamy S, et al. (2015) Neurokinin B administration induces hot flushes in women. Sci Rep 5: 8466 [Crossref]

37. Crandall CJ, Manson JE, Hohensee C, Horvath S, Wactawski-Wende J, et al. (2017) Association of genetic variation in the tachykinin receptor 3 locus with hot flashes and night sweats in the Women's Health Initiative Study. Menopause 24: 252-261. [Crossref]

38. Sowers MR, Wildman RP, Mancuso P, Eyvazzadeh AD, Karvonen-Gutierrez CA, et al. (2008) Change in adipocytokines and ghrelin with menopause. Maturitas 59: 149-157.

39. Whiteman MK, Staropoli CA, Langenberg PW, McCarter RJ, Kjerulff KH, et al. (2003) Smoking, body mass, and hot flashes in midlife women. Obstet Gynecol 101: 264-272. [Crossref]

40. Toffol E, Kalleinen N, Haukka J, Vakkuri O, Partonen T, et al. (2014) Melatonin in perimenopausal and postmenopausal women: associations with mood, sleep, climacteric symptoms, and quality of life. Menopause 21: 493-500. [Crossref]

41. Freedman RR (1998) Biochemical, metabolic, and vascular mechanisms in menopausal hot flashes. Fertil Steril 70: 332-337. [Crossref]

42. Freedman RR, Dinsay R (2000) Clonidine raises the sweating threshold in symptomatic but not in asymptomatic postmenopausal women. Fertil Steril 74: 20-23.

43. Gonzales GF, Carrillo C (1993) Blood serotonin levels in postmenopausal women: effects of age and serum oestradiol levels. Maturitas 17: 23-29. [Crossref]

44. Fink G, Sumner BE (1996) Oestrogen and mental state. Nature 383: 306. [Crossref]
45. Thurston RC, Chang Y, Buysse DJ, Hall MH, Matthews KA (2019) Hot flashes and awakenings among midlife women. Sleep 42.

46. Sievert LL (2013) Subjective and objective measures of hot flashes. Am J Hum Biol 25: $573-580$.

47. Santen RJ, Allred DC, Ardoin SP, Archer DF, Boyd N, et al. (2010) Postmenopausal hormone therapy: an Endocrine Society scientific statement. J Clin Endocrinol Metab 95: s1-s66. [Crossref]

48. Huang AJ, Cummings SR, Schembri M, Vittinghoff E, Ganz P, et al. (2016) Continuous transdermal nitroglycerin therapy for menopausal hot flashes: a single-arm, doseescalation trial. Menopause 23: 330-334. [Crossref]

49. Prague JK, Roberts RE, Comninos AN, Clarke S, Jayasena CN, et al. (2017) Neurokinin 3 receptor antagonism as a novel treatment for menopausal hot flushes: a phase 2, randomised, double-blind, placebo-controlled trial. Lancet 389: 1809-1820. [Crossref]

50. Oakley AE, Steiner RA, Chavkin C, Clifton DK, Ferrara LK, et al. (2015) kappa Agonists as a novel therapy for menopausal hot flashes. Menopause 22: 1328-1334. [Crossref]

51. Nelson HD, Vesco KK, Haney E, Fu R, Nedrow A, et al. (2006) Nonhormonal therapies for menopausal hot flashes: systematic review and meta-analysis. JAMA 295: 2057 2071. [Crossref]

52. Avis NE, Crawford SL, Greendale G, Bromberger JT, Everson-Rose SA, et al. (2015) Duration of menopausal vasomotor symptoms over the menopause transition. JAMA Intern Med 175: 531-539. [Crossref]

53. Parazzini F, Di Martino M, Pellegrino P (2017) Magnesium in the gynecologica practice: a literature review. Magnes Res 30: 1-7. [Crossref]

54. Huijgen HJ, Soesan M, Sanders R, Mairuhu WM, Kesecioglu J, et al. (2000) Magnesium levels in critically ill patients. What should we measure? Am J Clin Pathol 114: 688-695.

55. Altura BT, Memon ZI, Zhang A, Cheng TP, Silvermanet R, et al. (1997) Low levels of serum ionized magnesium are found in patients early after stroke which result in rapid elevation in cytosolic free calcium and spasm in cerebral vascular muscle cells. Neurosci Lett 230: 37-40. [Crossref]

56. Zehtabchi S, Sinert R, Rinnert S, Chang B, Heinis C, et al. (2004) Serum ionized magnesium levels and ionized calcium-to-magnesium ratios in adult patients with sickle cell anemia. Am J Hematol 77: 215-222. [Crossref]

57. Thurston RC, Sutton-Tyrrell K, Everson-Rose SA, Hess R, Matthews KA (2008) Hot flashes and subclinical cardiovascular disease: findings from the Study of Women's Health Across the Nation Heart Study. Circulation 118: 1234-1240. [Crossref]

58. Silveira JS, Clapauch R, Souza M, Bouskela E (2016) Hot flashes: emerging cardiovascular risk factors in recent and late postmenopause and their association with higher blood pressure. Menopause 23: 846-855. [Crossref]

59. Morais JBS, Severo JS, de Alencar GRR, de Oliveira ARS, Cruz KJC, et al. (2017) Effect of magnesium supplementation on insulin resistance in humans: A systematic review. Nutrition 38: 54-60. [Crossref]

60. Djurhuus MS, Skott P, Hother-Nielson O, Klitgaard NA, Beck-Nielsen H (1995) Insulin increases renal magnesium excretion: a possible cause of magnesium depletion in hyperinsulinaemic states. Diabet Med 12: 664-669.

61. Kim C, Edelstein SL, Crandall JP, Dabelea D, Kitabchi AE, et al. (2011) Menopause and risk of diabetes in the Diabetes Prevention Program. Menopause 18: 857-868. [Crossref]

62. Andreozzi F, Mannino GC, Mancuso E, Spiga R, Perticone F, et al. (2017) Plasma kisspeptin levels are associated with insulin secretion in nondiabetic individuals. PloS One 12: e0179834.

63. Natali A, Ribeiro R, Baldi S, Tulipani A, Rossi M, et al. (2013) Systemic inhibition of nitric oxide synthesis in non-diabetic individuals produces a significant deterioration in glucose tolerance by increasing insulin clearance and inhibiting insulin secretion. Diabetologia 56: 1183-1191. [Crossref]

64. Luheshi GN, Gardner JD, Rushforth DA, Loudon AS, Rothwell NJ (1999) Leptin actions on food intake and body temperature are mediated by IL-1. Proc Natl Acad Sci US A 96: 7047-7052. [Crossref]

65. Pandit R, Beerens S, Adan RAH (2017) Role of leptin in energy expenditure: the hypothalamic perspective. Am J Physiol Regul Integr Comp Physiol 312: R938-R47. [Crossref]

66. Dubins JS, Sanchez-Alavez M, Zhukov V, Sanchez-Gonzalez A, Moroncini G, et al. (2012) Downregulation of GPR83 in the hypothalamic preoptic area reduces core body temperature and elevates circulating levels of adiponectin. Metabolism 61: 1486-1493. [Crossref] 
67. Tom SE, Kuh D, Guralnik JM, Mishra GD (2010) Self-reported sleep difficulty during the menopausal transition: results from a prospective cohort study. Menopause 17: 1128-1135. [Crossref]

68. Abbasi B, Kimiagar M, Sadeghniiat K, Shirazi MM, Hedayati M, et al. (2012) The effect of magnesium supplementation on primary insomnia in elderly: A double-blind placebo-controlled clinical trial. J Res Med Sci 17: 1161-1169. [Crossref]
69. Rondanelli M, Opizzi A, Monteferrario F, Antoniello N, Manni R, et al. (2011) The effect of melatonin, magnesium, and zinc on primary insomnia in long-term care facility residents in Italy: a double-blind, placebo-controlled clinical trial. J Am Geriatr Soc 59: 82-90. [Crossref]

70. Cao Y, Zhen S, Taylor AW, Appleton S, Atlantis E, et al. (2018) Magnesium intake and sleep disorder symptoms: Findings from the Jiangsu nutrition study of Chinese adults at five-year follow-up. Nutrients 10: 1354. [Crossref]

Copyright: (C2021 Orlofsky M. This is an open-access article distributed under the terms of the Creative Commons Attribution License, which permits unrestricted use, distribution, and reproduction in any medium, provided the original author and source are credited. 